Special issue of the 3rd International Conference on Computational and Experimental Science and Engineering (ICCESEN 2016)

\title{
Magnetic Mesoporous Silica Nanocomposite for Biodiesel Production
}

\author{
S. ERDEM ${ }^{a, *}$, R.M. ÖKSÜZOĞLU ${ }^{b}$, S.B. AvŞAR ${ }^{c}$ ANd B. ERDEM ${ }^{c}$ \\ ${ }^{a}$ Uludag University, Physics Department, Bursa, Turkey \\ ${ }^{b}$ Anadolu University, Material Science and Engineering Department, Eskisehir, Turkey \\ ${ }^{c}$ Uludag University, Chemistry Department, Bursa, Turkey
}

\begin{abstract}
Ordered mesoporous silicas can be utilized as support because of having large surface area, tunable porosity, uniform pore size distribution, high thermal stability and modifiable properties. However, these materials introduce separation problems in liquid-phase processes. We have prepared $\mathrm{Fe}_{3} \mathrm{O}_{4}-\mathrm{SBA}-15-\mathrm{SO}_{3} \mathrm{H}$ solid acid catalyst by combining the properties of a magnetic material and the mesoporous character of silica. The sulfonic acid functionalized solid acid catalyst, containing both magnetic nanoparticles and mesoporous silica, is not only separable but also stable under hydrothermal conditions, which are usually employed for biodiesel production. Esterification of oleic acid with methanol for biodiesel production was carried out effectively and $75 \%$ conversion of ester was approximately reached within six hours in the presence of $\mathrm{Fe}_{3} \mathrm{O}_{4}-\mathrm{SBA}-15-\mathrm{SO}_{3} \mathrm{H}$ magnetic solid acid catalyst. In addition, the catalyst could be separated from the reaction system by applying external magnetic field and reused without deactivation.
\end{abstract}

DOI: 10.12693/APhysPolA.132.763

PACS/topics: 75.70.Cn, 88.20.fk

\section{Introduction}

Fatty acid ester, named also as biodiesel, is generally produced by means of esterification reaction between the vegetable oils and/or animal fats and alcohol over an acid catalyst [1]. Biodiesel has recently been paid attention since it is one of the sustainable energy resources [2]. Although the homogeneous catalysts can be used for biodiesel synthesis, the separation of the reaction components and the catalyst from the reaction mixture is difficult and also energy consuming, even if a high yield can be obtained $[3,4]$. Since oleic acid is the most common free fatty acid (FFA) found in the plant oil, which is abundant in the low-cost biodiesel feedstock, it is the most preferred FFA for evaluating the effectiveness of solid acid catalysts in esterification reaction [5].

Sulfonic acid functionalized ordered mesoporous material like $\mathrm{SBA}-15-\mathrm{SO}_{3} \mathrm{H}$ is an effective heterogeneous acid catalyst in the esterification reaction, due to large surface area, tunable porosity, narrow pore size distribution, and high thermal stability. However, the separation problem still continues to exist in the liquid-phase processes $[4,6]$. The magnetic mesoporous materials combining magnetite nanoparticles with mesoporous $\mathrm{SiO}_{2}$, have received great attentions because of their excellent magnetic properties, high surface area and pore volume, which are essential for the applications in catalysis, drug delivery, magnetic resonance imaging, biomolecular separation etc. [7]. The coating of $\mathrm{Fe}_{3} \mathrm{O}_{4}$ nanoparticles with an open mesopore structure not only exhibits catalytic

*corresponding author; e-mail: serdem@uludag.edu.tr activity after functionalization, but also prevents from aggregation and degradation of $\mathrm{Fe}_{3} \mathrm{O}_{4}$ nanoparticles by isolating them from each other [8].

Herein, we report the synthesis of the magnetic solid acid catalyst through a modified direct synthetic method and its utilization for production of biodiesel. The sulfonic acid-functionalized catalyst containing both magnetic nanoparticles and mesoporous structures is not only separable but is also stable under hydrothermal conditions, which are usually employed for biodiesel production. This material not only enhances the esterification of oleic acid with methanol, but also facilitates the catalyst separation. By combining the active catalytic and magnetic characteristics, we have omitted an energy-consuming process needed to separate the solid acid.

\section{Experimental}

We have prepared the $\mathrm{Fe}_{3} \mathrm{O}_{4}$-SBA-15- $\mathrm{SO}_{3} \mathrm{H}$ catalyst by using the direct synthetic method as described elsewhere [3], in the presence of magnetic $\mathrm{Fe}_{3} \mathrm{O}_{4}$ nanoparticles $(<40 \mathrm{~nm})$, triblock copolymers Pluronic P123 and hydrogen peroxide. In a typical synthesis, $2 \mathrm{~g}$ of $\mathrm{Fe}_{3} \mathrm{O}_{4}$ nanoparticles were added to homogeneous solution of Pluronic P123 in $0.5 \mathrm{M} \mathrm{HCl}$ under $\mathrm{N}_{2}$ atmosphere. After stirring for $2 \mathrm{~h}$, tetraethoxysilane, as silica source, was added, followed by additional stirring for $3 \mathrm{~h}$ at $40^{\circ} \mathrm{C}$. For sulfonic acid functionalization 3-mercaptopropyltrimethoxysilane and $\mathrm{H}_{2} \mathrm{O}_{2}$ were added at once and the mixture was stirred for $20 \mathrm{~h}$ at $40^{\circ} \mathrm{C}$.

Then the mixture was aged in Teflon bottle at $100^{\circ} \mathrm{C}$ for $24 \mathrm{~h}$ and filtrated before drying at $60^{\circ} \mathrm{C}$ under vacuum. Finally, the sample material was refluxed with ethanol for $24 \mathrm{~h}$, filtrated and dried under vacuum. For comparison test, the solid acid catalyst without addition 
of magnetic nanoparticles (SBA-15- $\left.\mathrm{SO}_{3} \mathrm{H}\right)$ was also prepared. Low and high angle XRD, FT-IR, $\mathrm{N}_{2}$ adsorption/desorption, EDX and VSM analysis techniques were used for characterization. The catalytic activity was investigated for oleic acid-methanol esterification. In addition, the catalyst was directly reused after filtration for the following four runs and no excessive catalytic activity drop was observed.

\section{Results and discussion}

Figure 1a and $\mathrm{b}$ shows the small and high angle XRD patterns of $\mathrm{SBA}-15-\mathrm{SO}_{3} \mathrm{H}$ and $\mathrm{Fe}_{3} \mathrm{O}_{4}-\mathrm{SBA}-15-$ $\mathrm{SO}_{3} \mathrm{H}$ samples. Both of them exhibit diffraction peak around $2 \theta \approx 0.8^{\circ}-0.9^{\circ}$, corresponding to (100) diffraction, which is characteristic for a hexagonal mesoporous structure with $p 6 m m$ symmetry. However, the reduced intensity of the peak discloses that the ordering degree decreases due to the insertion of $\mathrm{Fe}_{3} \mathrm{O}_{4}$ into the mesoporous silica. The retention of this peak after magnetic derivation indicates that the ordered mesoporous structure was maintained in the magnetic solid acid catalyst (Fig. 1a).
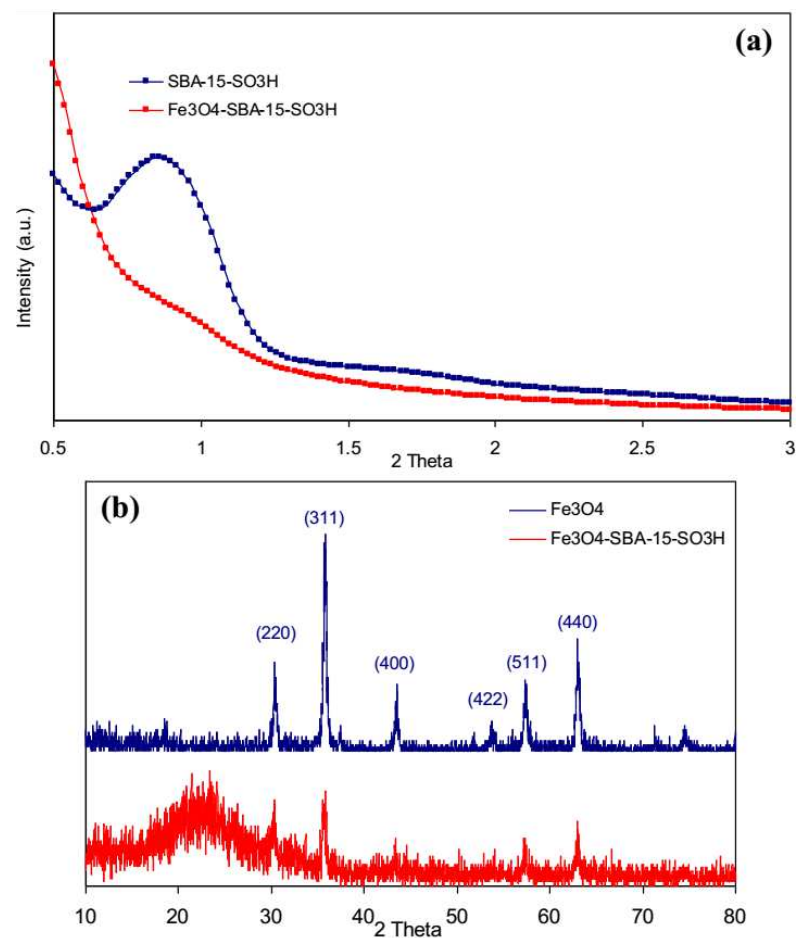

Fig. 1. Low angle XRD patterns of SBA-15- $\mathrm{SO}_{3} \mathrm{H}$ and $\mathrm{Fe}_{3} \mathrm{O}_{4}$-SBA-15- $\mathrm{SO}_{3} \mathrm{H}$ samples (a) and high angle XRD patterns of $\mathrm{Fe}_{3} \mathrm{O}_{4}$ and $\mathrm{Fe}_{3} \mathrm{O}_{4}-\mathrm{SBA}-15-\mathrm{SO}_{3} \mathrm{H}$ samples (b).

At high angles, the observed XRD patterns corresponding to the values of Miller indices $\{\mathrm{hkl}\}$ of (220), (311), (400), (422), (511) and (440) reveal cubic iron oxide phase, the structure of which is inverse spinel ferrite of magnetite. The peak around $23^{\circ}$ corresponds to the amorphous silica matrix. The position and relative intensities of all XRD patterns of $\mathrm{Fe}_{3} \mathrm{O}_{4}$ match well with the peaks of $\mathrm{Fe}_{3} \mathrm{O}_{4}-\mathrm{SBA}-15-\mathrm{SO}_{3} \mathrm{H}$, indicating the maintenance of the crystalline structure. It was concluded from the XRD patterns, that both of the frameworks of the $\mathrm{Fe}_{3} \mathrm{O}_{4}$ and $\mathrm{Fe}_{3} \mathrm{O}_{4}-\mathrm{SBA}-15-\mathrm{SO}_{3} \mathrm{H}$ samples do not collapse.

Representative FT-IR spectra of the samples are shown in Fig. 2. The water in the samples can be observed by following the absorption lines at 3500 and $1640 \mathrm{~cm}^{-1}$, on the other hand $\mathrm{Si}-\mathrm{OH}$ can be observed as a shoulder at $960 \mathrm{~cm}^{-1}$. The peak around $1100 \mathrm{~cm}^{-1}$ is assigned to $\mathrm{Si}-$ O stretching vibrations. The weaker peak at approximately $800 \mathrm{~cm}^{-1}$ corresponds to the symmetric stretching vibration of the $\mathrm{Si}-\mathrm{O}$ network. In fact, the $\mathrm{S}=\mathrm{O}$ asymmetric stretching $\left(\mathrm{SO}_{2}\right)$ vibrational mode is clearly visible at around $1350 \mathrm{~cm}^{-1}$ and the $\mathrm{S}-\mathrm{OH}$ stretching vibration of $\mathrm{SO}_{3} \mathrm{H}$ at $840 \mathrm{~cm}^{-1}$ was also observed [9]. On the other hand, the band around $1200-1100 \mathrm{~cm}^{-1}$ becomes much broader than that of SBA-15-SO $\mathrm{SO}_{3} \mathrm{H}$. All these observations confirm that the sulfonyl groups have functionalized both of the surface of SBA-15- $\mathrm{SO}_{3} \mathrm{H}$ and $\mathrm{Fe}_{3} \mathrm{O}_{4}$-SBA-15$\mathrm{SO}_{3} \mathrm{H}$ samples. An additional peak has appeared in the spectra of $\mathrm{Fe}_{3} \mathrm{O}_{4}-\mathrm{SBA}-15-\mathrm{SO}_{3} \mathrm{H}$. This peak, seen around $660 \mathrm{~cm}^{-1}$, can be attributed to the iron-oxygen bonds within the mesoporous silica [8].

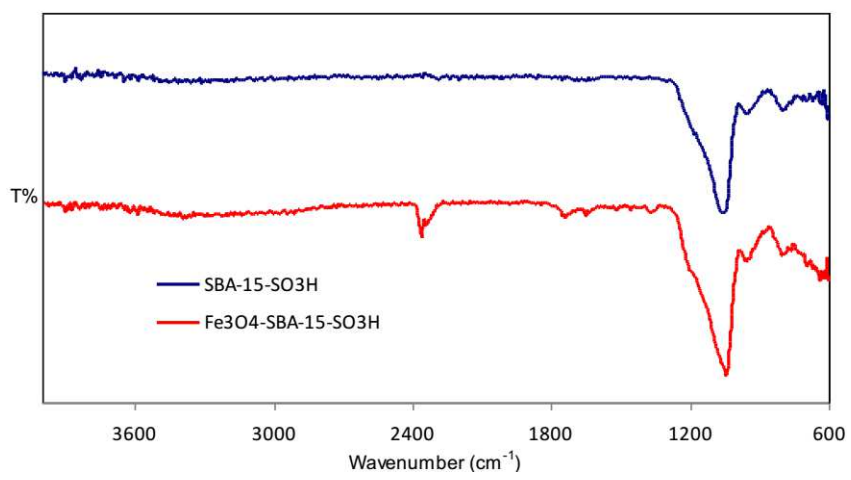

Fig. 2. FT-IR spectra of SBA-15- $\mathrm{SO}_{3} \mathrm{H}$ and $\mathrm{Fe}_{3} \mathrm{O}_{4}$ SBA-15- $\mathrm{SO}_{3} \mathrm{H}$ samples.

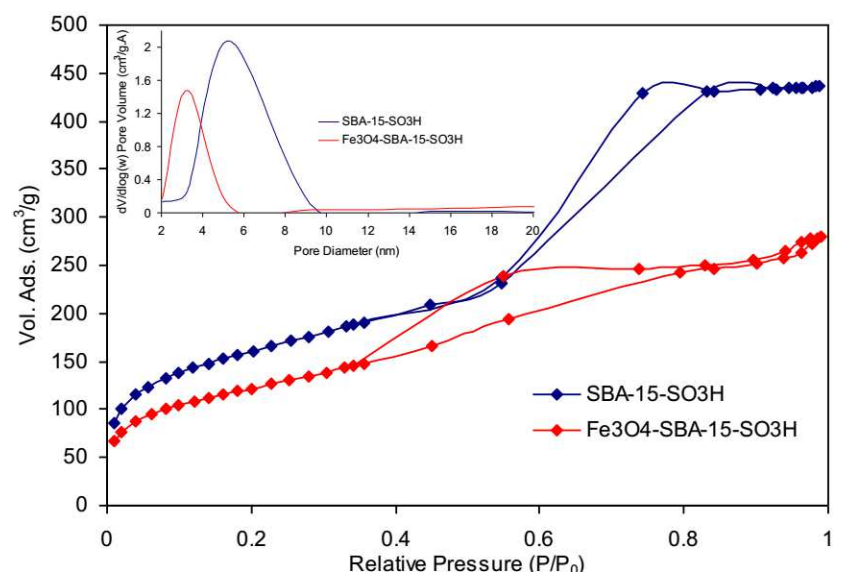

Fig. 3. $\mathrm{N}_{2}$ adsorption/desorption isotherms of SBA15- $\mathrm{SO}_{3} \mathrm{H}$ and $\mathrm{Fe}_{3} \mathrm{O}_{4}-\mathrm{SBA}-15-\mathrm{SO}_{3} \mathrm{H}$ samples (pore size distributions are shown in the inset). 
As shown in Fig. 3, both of the samples show typical type IV isotherms with a sharp capillary condensation step in the relative pressure $\mathrm{p} / \mathrm{p}_{0}$ range of $0.4-0.8$, indicating the mesoporous structures and narrow pore size distribution (as also shown in the inset of Fig. 3) [7]. Additionally, $\mathrm{Fe}_{3} \mathrm{O}_{4}-\mathrm{SBA}-15-\mathrm{SO}_{3} \mathrm{H}$ had shown excellent textural properties, such as high surface area, large pore diameter and high pore volume, as can be seen in Table I. All results indicate that not only $\mathrm{Fe}_{3} \mathrm{O}_{4}$ nanoparticles could be embedded into the mesoporous silica, but also mesoporous structure could be maintained.

TABLE I

Textural and magnetic properties of SBA-15- $\mathrm{SO}_{3} \mathrm{H}, \mathrm{Fe}_{3} \mathrm{O}_{4}$ and $\mathrm{Fe}_{3} \mathrm{O}_{4}$-SBA-15-SO $\mathrm{SO}_{3} \mathrm{H}$ samples.

\begin{tabular}{c|c|c|c|c|c}
\hline \hline Samples & $\begin{array}{c}\mathrm{M}_{s} \\
{[\mathrm{emu} / \mathrm{g}]}\end{array}$ & $\begin{array}{c}H_{\mathrm{c}} \\
{[\mathrm{Oe}]}\end{array}$ & $\begin{array}{c}V_{\text {pore }} \\
{\left[\mathrm{cm}^{3} / \mathrm{g}\right]}\end{array}$ & $\begin{array}{c}S_{\text {BET }} \\
{\left[\mathrm{m}^{2} / \mathrm{g}\right]}\end{array}$ & $\begin{array}{c}d_{\text {pore }} \\
{[\mathrm{nm}]}\end{array}$ \\
\hline $\mathrm{SBA}-15-\mathrm{SO}_{3} \mathrm{H}$ & - & - & 0.63 & 546.3 & 4.8 \\
$\mathrm{Fe}_{3} \mathrm{O}_{4}$ & 73.1 & 89.0 & - & - & - \\
$\mathrm{Fe}_{3} \mathrm{O}_{4}-\mathrm{SBA}_{-15-\mathrm{SO}_{3} \mathrm{H}}$ & 12.1 & 82.6 & 0.42 & 421.6 & 3.6
\end{tabular}

Magnetic hysteresis curves obtained using vibrating sample magnetometer at room temperature are shown in Fig. 4. Although $\mathrm{Fe}_{3} \mathrm{O}_{4}$ nanoparticles have a saturation magnetization value of $73.1 \mathrm{emu} / \mathrm{g}$, coating of these nanoparticles with the mesoporous silica layer has reduced this value to $12.1 \mathrm{emu} / \mathrm{g}$. The decrease in the magnetization can be understood as a consequence of some structural changes at the silica-magnetite interface, which resulted in the decrease of interactions between the spins at the surface of the nanoparticles [8]. A reduction in the coercivity is also observed (Fig. 4, inset), however the nanocomposite has kept the ferromagnetic character at room temperature. Even with this reduction in the saturation magnetization, $\mathrm{Fe}_{3} \mathrm{O}_{4}-\mathrm{SBA}-15-\mathrm{SO}_{3} \mathrm{H}$ sample can still be efficiently and easily separated from solution by using an external magnetic force.

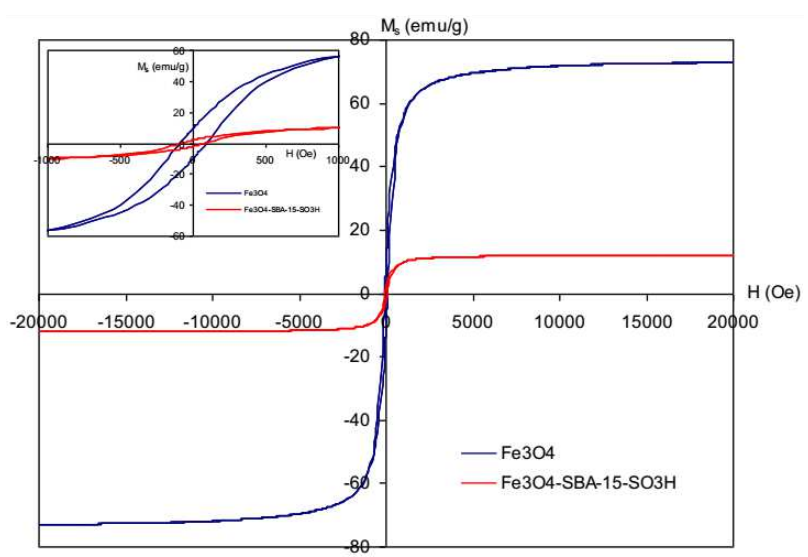

Fig. 4. Magnetization curves for $\mathrm{Fe}_{3} \mathrm{O}_{4}$ and $\mathrm{Fe}_{3} \mathrm{O}_{4}-$ SBA-15- $\mathrm{SO}_{3} \mathrm{H}$ at room temperature between -20 and $+20 \mathrm{kOe}(-1$ and $+1 \mathrm{kOe}$, inset)

The elemental compositions were analyzed with the energy-dispersive X-ray spectroscope (EDX), as shown in Fig. 5. It is clear from Fig. 5, that Si peak decreases with the emergence of Fe peak, demonstrating that magnetite nanoparticles could penetrate into the mesostructure without damaging.

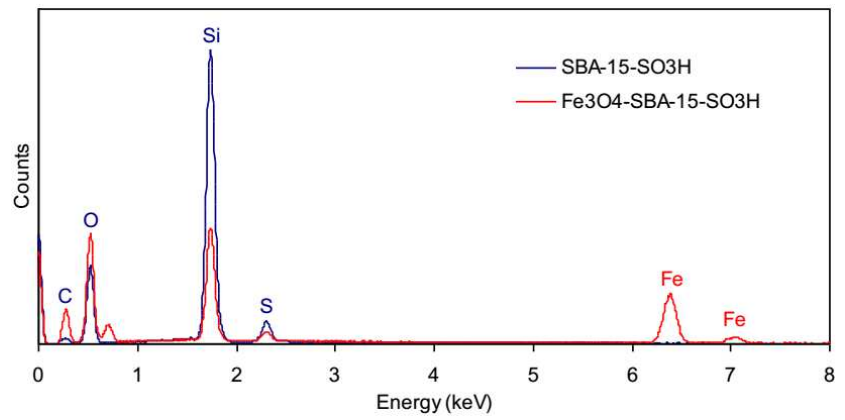

Fig. 5. EDX spectra for $\mathrm{SBA}-15-\mathrm{SO}_{3} \mathrm{H}$ and $\mathrm{Fe}_{3} \mathrm{O}_{4}$ SBA-15- $\mathrm{SO}_{3} \mathrm{H}$ samples.

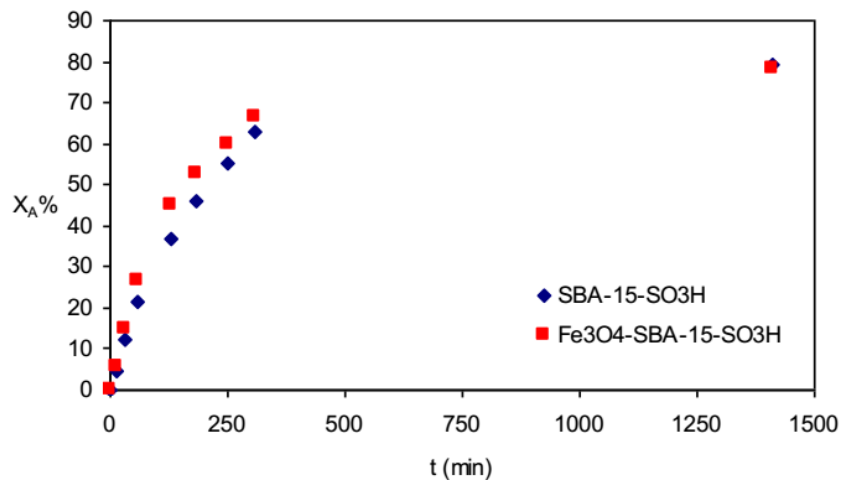

Fig. 6. Oleic acid conversions for $\mathrm{SBA}-15-\mathrm{SO}_{3} \mathrm{H}$ and $\mathrm{Fe}_{3} \mathrm{O}_{4}$-SBA- $15-\mathrm{SO}_{3} \mathrm{H}\left(60^{\circ} \mathrm{C}, 500 \mathrm{rpm}, 0.5 \mathrm{~g}\right.$ catalyst $)$.

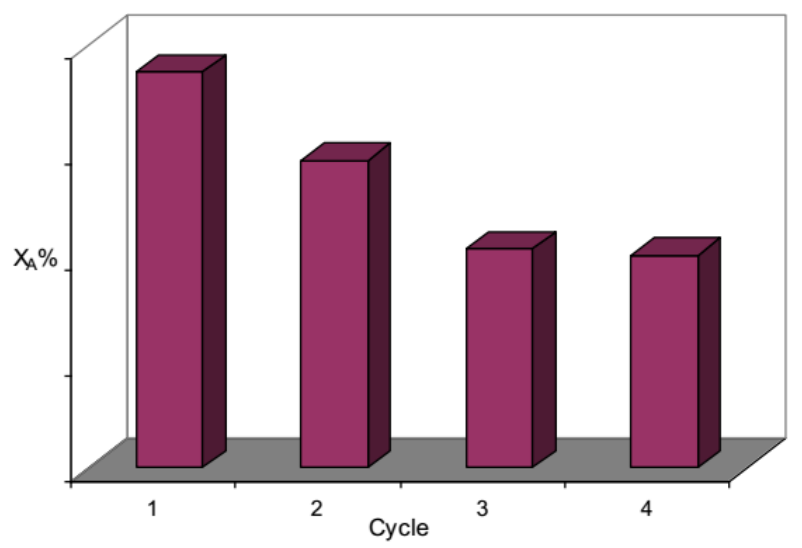

Fig. 7. Catalytic performance over four cycles.

SBA-15- $\mathrm{SO}_{3} \mathrm{H}$ and $\mathrm{Fe}_{3} \mathrm{O}_{4}-\mathrm{SBA}-15-\mathrm{SO}_{3} \mathrm{H}$ were catalytically tested for oleic acid-methanol esterification and both of the catalysts were found to be comparably active, as can be seen from Fig. 6. Furthermore, $\mathrm{Fe}_{3} \mathrm{O}_{4}$-SBA-15$\mathrm{SO}_{3} \mathrm{H}$ was easily separated from the resulting mixture in a magnetic field and can be used repeatedly without 
deactivation. In this study, the catalyst was directly reused after magnetic separation for the following runs and could be reused four times successfully (Fig. 7).

\section{Conclusions}

The characterization and the catalytic activity results, obtained for $\mathrm{Fe}_{3} \mathrm{O}_{4}-\mathrm{SBA}-15-\mathrm{SO}_{3} \mathrm{H}$, have shown that the magnetic character of $\mathrm{Fe}_{3} \mathrm{O}_{4}$ was maintained, even if it was coated with silica layer and it was more catalytically active for biodiesel synthesis, compared with SBA$15-\mathrm{SO}_{3} \mathrm{H}$. Furthermore, $\mathrm{Fe}_{3} \mathrm{O}_{4}-\mathrm{SBA}-15-\mathrm{SO}_{3} \mathrm{H}$ was easily separated from the reaction mixture without deactivation. In summary, both, the efficient production of biodiesel and easy separation of catalyst were achieved by using $\mathrm{Fe}_{3} \mathrm{O}_{4}-\mathrm{SBA}-15-\mathrm{SO}_{3} \mathrm{H}$. High conversion in a short reaction time and reusability of $\mathrm{Fe}_{3} \mathrm{O}_{4}-\mathrm{SBA}-15-\mathrm{SO}_{3} \mathrm{H}$ are remarkable in terms of economical and environmental applications of the process.

\section{Acknowledgments}

This work was supported by The Commission of Scientific Research Projects of Uludag University, Project number: OUAP(F)-2015/21 and KUAP(F)-2014/33.

\section{References}

[1] O. Ilgen, Fuel Proc. Technol. 124, 134 (2014).

[2] K. Yilancioğlu, H.O. Tekin, S. Cetiner, Acta Phys. Pol. A 130, 428 (2016).

[3] D.-M. Lai, L. Deng, J. Li, B. Liao, Q.-X. Guo, Y. Fu, Chem. Sus. Chem. 4, 55 (2011)

[4] D.-M. Lai, L. Deng, Q.-X. Guo, Y. Fu, Ener. Environ. Sci. 4, 3552 (2011).

[5] Y. Zhang, W.T. Wong, K.F. Yung, Appl. Ener. 116, 191 (2014).

[6] A.H. Lu, W.C. Li, A. Kiefer, W. Schmidt, E. Bill, G. Fink, F. Schüth, J. Am. Chem. Soc. 126, 8616 (2004).

[7] J. Wei, L. Zou, J. Porous Mater. 23, 577 (2016).

[8] K.C. Souza, G. Salazar-Alvarez, J.D. Ardisson, W.A.A. Macedo, E.M.B. Sousa, Nanotechnol. 19, 185603 (2008).

[9] S. Jeenpadiphat, E.M. Björk, M. Oden, D.N. Tungasmita, J. Molecular Catal. A: Chem. 410, 253 (2015). 